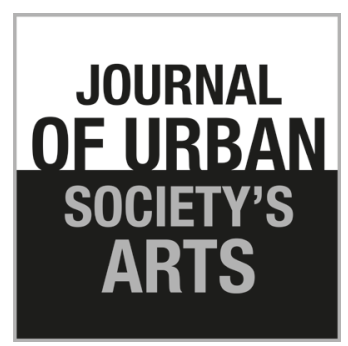

Volume 5 Nomor 1, April 2018: 49-57

\section{Para Harimau yang Menolak Punah: Estetika Dokumenter Televisi di Era Pasca Reformasi}

\author{
Romdhi Fatkhur Rozi dan Renta Vulkanita Hasan
}

Program Studi Televisi dan Film, Fakultas Ilmu Budaya, Universitas Jember Jl. Kalimantan No. 37 Tegal Boto Jember Jawa Timur

Tlp. 081328880986,E-mail: romdhi_fatkhur_rozi@yahoo.co.id

\begin{abstract}
ABSTRAK
Para Harimau Yang Menolak Punah (Imanda Dea Sabiella dan Edho Cahya Kusuma, 2013) merupakan judul dokumenter televisi produksi Eagle Institute dengan ciri filmis berupa paduan antara gambar dan tuturan (wawancara). Dokumenter ini merupakan objek material yang menarik untuk diteliti dalam konteks kontinuitas dan perubahan estetika, selama era pasca reformasi dengan zaman Orde Baru sebagai pembanding. Jika pada masa orde baru, kampanye pelestarian lingkungan melalui media dokumenter notabene diproduksi oleh pemerintah melalui estetika sinematik yang bersifat propagandis, maka saat ini dokumenter produksi Eagle Institute justru menggunakan estetika sinematik yang kritis sebagai konter bagi pemerintah. Fakta dan fiksi (faksi) menjadi istilah yang digunakan dalam penelitian ini sebagai bentuk kontinuitas dan perubahan dokumenter televisi Indonesia. Alasan pemilihan istilah ini adalah dunia fenomenal dalam banyak kasus, seperti yang terlihat dalam dokumenter, seakan berbeda dari "dunia nyata", meskipun dalam kenyataannya rekaman itu berasal dari "dunia nyata/realitas". Penelitian ini menggunakan pendekatan film kognitif untuk mengamati sejauh mana Faksi beroperasi sebagai media kritik yang secara estetis merangkai dokumenter tersebut. Struktur mental digunakan untuk menjelaskan Faksi melalui petunjuk filmis hingga diperoleh kesimpulan tentang kritik yang ingin disampaikan melalui dokumenter.
\end{abstract}

Kata kunci: estetika; dokumenter; pasca reformasi; faksi

\begin{abstract}
Para Harimau Yang Menolak Punah (Imanda Dea Sabiella dan Edho Cahya Kusuma, 2013) is the title of a television documentary produced by Eagle Institute. The documentary has characters that specifically contains of expository shots. This documentary is an interesting material object to be examined in the context of continuity and aesthetic change, during the post-reform era with the New Order era as a comparison. During the new order era, environmental conservation campaigns through documentary media were produced by the government through propagandist cinematic aesthetics. Whereas, the post-reform documentary produced by Eagle Institute actually uses a critical cinematic aesthetic as a counter for the government. Fact and fiction (faction) became the term used in this study as a form of continuity and change of Indonesia documentary. The reason for choosing this term is the phenomenal world in many cases, as seen in the documentary, as though it were different from the "real world", even though in reality it came from "the real world". This study uses a cognitive film approach to observe the extent to which the Faction operates as a criticism medium which aesthetically assembles the documentary. The mental structure is used to explain the Faction through filmic clues to the conclusion of the criticism that the documentary wishes to convey.
\end{abstract}

Keywords: aesthetic; documentary; post-reform; faction 


\section{Pendahuluan}

Dokumenter menjadi salah satu bahasan yang menarik dalam wacana perfilman di Indonesia, khususnya ketika wacana itu berangkat dari periodisasi yang membaginya ke dalam masa orde baru dan pascareformasi. Estetika dan politik merupakan hal yang hampir selalu 'disinggungkan' dalam wilayah tekstual dan kontekstual pada kedua masa itu. Tentu saja ini menarik untuk dikaji dengan alasan bahwa 'persinggungan' itu barangkali (suatu saat) akan menjadi paradoks bagi dokumenter Indonesia. Kajian ini tidak mengupas hasil dari persinggungan antara yang tekstual dengan yang kontekstual. Kajian ini justru akan fokus pada penyelidikan terhadap wacana tentang upaya untuk 'menyinggungkan' teks dengan konteks melalui wilayah estetika dan politik. Sebagai bekal bagi penyelidikan awal, peneliti mengemukakan hipotesis terhadap upaya persinggungan antara teks dengan konteks dalam dokumenter Indonesia. Hipotesis ini berlandaskan kepada pemahaman peneliti terhadap wacana terdahulu yang menyebutkan bahwa dokumenter Indonesia di masa orde baru cenderung sebagai propaganda berbalut karya seni dan di masa pascareformasi 1998 sebagai karya seni yang sarat kritik, sehingga hipotesis ini menyebutkan definisi sederhana bahwa (1) dokumenter itu adalah suatu karya seni dan (2) dokumenter itu adalah propaganda. ${ }^{1}$

Salah satu film dokumenter yang diproduksi pasca reformasi adalah "Para Harimau Yang Menolak Punah" karya Imanda Dea Sabiella (Manda) dan Edho Cahya (Edho). Film ini menarik untuk dikaji karena karya dokumenter tersebut merupakan karya film pertama dari kedua sutradara, dan mendapat kesempatan untuk diproduksi setelah lolos seleksi dalam ajang kompetisi film dokumenter Eagle Award. ${ }^{2}$ Dokumenter ini diproduseri oleh Kioen Moe yang merupakan ketua umum dari pengurus yayasan Eagle Institute. Film ini merupakan salah satu potret dimana produk dokumenter-estetik, lahir dalam konteks politik tertentu. Konteks pasca reformasi, dan konteks bahwa film ini diproduseri oleh sebuah yayasan yang bertujuan untuk melahirkan suatu gerakan publik yang konkrit dalam memperlihatkan peran masyarakat sipil mengawal kehidupan berbangsa dan bernegara.

Sebagai produk dokumenter, karya Manda dan Edho ini berbicara tentang bagaimana gerakan rakyat menolak keberadaan tambang liar yang ada di kawasan Taman Nasional Meru Betiri. Film ini memiliki struktur bertutur kritis atas eksploitasi alam yang luput dari perhatian pemerintah. Meskipun membicarakan tentang fenomena yang faktual, film ini tentu tidak bisa dilepaskan begitu saja dari aspek aspek estetik yang sengaja dimunculkan dalam film. Untuk menelaah lebih jauh tentang bagaimana relasi antara unsur faktual dan estetik dalam film dokumenter tersebut, peneliti mencoba merasionalisasi hipotesis yang dibangun dengan cara merujuk kepada pendapat Flaherty dan Grierson.

Perlakuan kreatif terhadap aktualitas merupakan definisi Grierson atas dokumenter. Meskipun sepakat, Flaherty menyatakan bahwa perlakuan tersebut tidak hanya mengedepankan aktualitas, namun diperlukan juga perlakuan kreatif atas aktualitas yang direkam. Grierson cenderung fokus terhadap analisis gambar, sementara Flaherty menekankan aspek editing gambar. Hal itulah yang membedakan pemahaman tentang dokumenter antara Flaherty dengan Grierson (Ellis, 1989: 5). Sementara itu, Paul Rotha yang merasa bahwa argumentasi Grierson bertele-tele, namun juga tanpa memihak pernyataan Flaherty, melihat bahwa dokumenter merupakan sebuah kejadian nyata yang secara sengaja ditampilkan dalam film. Hal ini dimaksudkan untuk mencapai sesuatu yang lain, yaitu menghibur penonton dan menghasilkan

$1 \quad$ Periksa Budi Irawanto, Beyond Big Dramatic Moment: Indonesian Documentary Films in the $21^{s t}$ Century, (Busan: Busan International Film Festival, 2012). Setidaknya, melalui artikel yang ditulis oleh Irawanto, penulis menangkap wacana tentang posisi dokumenter Indonesia sejak masa orde baru hingga pascareformasi 1998.

2 Eagle Award diselenggarakan oleh Metro TV yang mengkhususkan pada film dokumenter bagi sineas muda khususnya mahasiswa di Indonesia. 
uang. Kesengajaan itu direfleksikan Rotha melalui empat tradisi, yaitu: naturalis, newsreel (warta berita), propaganda, dan realis. Tradisi tersebut menandai perkembangan dokumenter yang muncul pada abad kedua puluh, dan diciptakan dalam arti untuk memenuhi kebutuhan artistik dan komunikasi (Ellis, 1989: 7). Melalui perbedaan yang muncul secara subjektif tersebut, lantas apa kiranya dasar atau pakem yang membuat dokumenter memiliki definisi yang berbeda dengan tipe film yang lain? Dokumenter selalu didefinisikan secara relasional dan komparatif, sehingga dokumenter di sini selalu diartikan berlawanan dengan film fiksi, eksperimental, dan film avant-garde (Nichols, 2001: 20). Dokumenter merupakan representasi atas dunia yang kita diami melalui suatu proses yang dinamakan reproduksi realitas. Reproduksi realitas pada dokumenter tidak semata-mata sebagai konsep pasti, namun justru cenderung menjadi konsep yang "kabur". Lebih dalam Bill mengemukakan:

"Tidak semua dokumenter menunjukkan satu rangkaian karakteristik bersama. Praktek film dokumenter adalah arena di mana hal-hal berubah. Pendekatan alternatif terus diusahakan dan kemudian diadopsi oleh orang lain atau ditinggalkan. Saat itulah kontestasi terjadi" (Nichols, 2001: 21).

Kontestasi yang terjadi dalam citra dokumenter tersebut merupakan bukti keberadaan tradisi propaganda yang secara politis mengaburkan persoalan estetis. Kekaburan yang terjadi akibat benturan aspek estetis dan politis rupanya cukup menyulitkan teorisasi dalam dokumenter dalam menyatakan keindahan dan kebenaran. Setidaknya ada empat sudut pandang berbeda yang dapat digunakan sebagai pendekatan dalam mendefinisikan dokumenter. Empat hal tersebut adalah: (1) institusi; (2) praktisi/pelaku; (3) teks (film/video); dan (4) penonton (Nichols, 2001: 22).

Merujuk pada pendefinisian dokumenter tersebut, untuk mendapatkan tinjauan mendalam atas film 'Para Harimau Yang Menolak Punah' maka peneliti juga melakukan wawancara dengan salah seorang sutradaranya (Manda). Selain itu peneliti juga menempatkan diri sebagai penonton, untuk melengkapi sudut pandang. Dengan melihat Eagle Award melalui Yayasan Eagle Institute sebagai institusi dibalik karya dokumenter ini, wawancara terhadap sineas, mengkaji teks estetis film, serta bertindak sebagai penonton, maka diharapkan mampu mendapatkan tinjauan yang komprehensif atas kajian ini. Terutama, tentang bagaimana estetika dokumenter televisi ketika berhubungan dengan konteks politik era pasca reformasi.

Aspek estetik dalam dokumenter dapat dikatakan merupakan intervensi kreatif dalam memvisualkan apa yang faktual ke dalam film, dengan serangkaian naskah, sentuhan saat produksi dan keputusan untuk memilah shot apa yang akan ditayangkan dan mana yang tidak. Memang, sebuah karya non-fiksi seperti dokumenter juga berisi sejumlah elemen fiktif yang merupakan intervensi kreatif sebagai representasi yang bertujuan untuk memperlihatkan adanya pertemuan dalam sebuah dunia. Materi elemen fiktif tersebut antara lain pembangunan karakter (sebagai contoh Flaherty dengan film Nanook of The North) yang muncul melalui jalan lain untuk menunjukkan kategori ideal (semacam heroik dan genius); penggunaan bahasa puitis; naratif; atau iringan musik untuk meningkatkan dampak emosional atau penciptaan ketegangan melalui narasi dan bagian dramatis yang tertanam (saat kisah diceritakan oleh subjek yang diwawancarai, saat itulah terjadi struktur krisis pada pemikiran penonton) (Renov, 1993: 2).

Persoalan dokumenter yang terkait dengan aspek estetik dan politik dalam penyampaian kebenaran dan keindahan, disinggung oleh Ellis dengan kerangka berpikir sebagai berikut:

"Karakter dokumenter umumnya memiliki kesamaan yang berbeda dengan tipe film lainnya (khususnya dari film fiksi) dalam beberapa hal yang dianggap: 1) Subjek; 2) tujuan, pandangan, atau pendekatan; 3) bentuk-bentuk; 4) metode produksi dan teknis; 5) pengalaman singkat yang ditawarkan kepada penonton (Ellis, 1989: 2).”

Renov melalui pengantar yang berjudul "kebenaran tentang non-fiksi" mencoba merangkum beberapa pernyataan dan rumusan terkait dokumenter dengan penekanan relasi ontologis dan epistimologis yang disampaikan sebagai berikut: 
"Dalam hal ini, pada kenyataannya, keyakinan saya menyatakan bahwa kajian ini merupakan buah refleksi atas seluruh rangkaian interval-antara kebenaran dan keindahan, kebenaran dan realitas, ilmu pengetahuan dan seni, fiksi dan nonfiksi, konstatif dan performatif, representasi diri dan liputan media, sejarah dan teori, dengan melalui cara signifikan dalam memajukan pemikiran saat ini, tentang video dan film dokumenter" (Renov, 1993: 10).

Wacana pengetahuan yang dirumuskan oleh Brian Winston (1988) cukup menarik untuk membahas persoalan posisi dokumenter yang selalu menjadi perdebatan atas "persinggungannya" dengan film fiksi. Sebut saja tindakan Flaherty yang melakukan strukturisasi pada aktualitas material mungkin memberikan kepuasan yang cukup bagi Grierson atau yang lain dalam menemukan bentuk baru pada dokumenter. Tetapi kebutuhan akan struktur tersebut secara implisit berlawanan dengan adanya gagasan atas aktualitas yang tidak terstruktur. Direct cinema dan cinema verite lahir sebagai hasil dari kritik radikal Morin dan Rouch atas aktualitas yang tidak terstruktur. Kemunculan cinema verite sekaligus merupakan tanda retoris yang memunculkan batasan manipulasi terkait gagasan yang memengaruhi hal-hal masuk akal serta pernyataan dramatis terkait dokumenter (Winston, 1988: 25). Seperti pernyataan Winston berikut:

"Dokumenter memiliki persamaan dengan film fiksi, tetapi masing-masing memiliki perbedaan yang ditekankan pada tingkat kesulitan, namun tingkat kesulitan belum dapat melegitimasi perbedaan tersebut. Dampak dari gaya vérité mengurangi kekakuan atas perbedaan dan persoalan legitimasi, di mana saat kedua film diletakkan secara bersama-sama, yang mana hal itu juga menambah elemen khusus bagi masing-masing selama pemfilman" (Winston, 1988: 33).

Peneliti mengamati bahwa beberapa rujukan pustaka atau penelitian terdahulu mengarahkan peneliti kepada pemahaman tentang dua hal, yaitu fakta dan fiksi dalam dokumenter. Peneliti memahami bahwa unsur fakta yang disajikan dalam dokumenter ternyata berbatasan secara "tipis" dengan unsur fiksi, di mana wilayah estetis menjadi cukup politis dalam periode dokumenter di masa orde baru maupun pascareformasi 1998. Pemahaman peneliti dalam hal ini perlu diuji dengan menggunakan pendekatan film kognitif agar keberadaan fakta dan fiksi terutama aspek aspek estetis dalam dokumenter benar-benar "dialami" melalui pembacaan terhadap petunjuk filmis yang terdapat di sepanjang plot. Fakta dan Fiksi (Faksi) dalam dokumenter sebenarnya bukan "istilah" baru. Dalam hal ini peneliti memandang bahwa penggunaan istilah fakta dan fiksi (Faksi) bagi dokumenter era pascareformasi cukup relevan karena dua hal, yaitu: legitimasi dan makna (Hasan, 2016: $164-171) .^{3}$

\section{Pembahasan}

Relasi fakta dan fiksi tercermin dalam dokumenter "Para Harimau Yang Menolak Punah", terutama pada kapasitas film tersebut sebagai sebuah produk dokumenter, dan bagaimana film tersebut dikemas secara estetis. Hal ini akan tampak dari pemilihan judul, shot-shot yang dengan sengaja dipilih untuk ditampilkan, dan retorika yang dibangun tentang konflik sebagai ide cerita dengan subyektifitas dan keberpihakan sineas. Subyektifitas dan keberpihakan misalnya melalui pemilihan narasumber, dan volume sajian yang tidak berimbang antara kedua pihak yang

\footnotetext{
Peneliti pernah melakukan penyelidikan awal terhadap dokumenter televisi produksi Eagle Institute berjudul Joki Kecil, yang merupakan pemenang pertama dalam kompetisi Eagle Award 2005. Hasil penelitian itu menunjukkan bahwa persinggungan antara estetika dan politik pada dokumenter pascareformasi telah dimulai pada tahun 2005 oleh Eagle. Meskipun tidak ditemukan metafora pada judulnya sebagai penanda Faksi seperti pada judul dokumenter dalam penelitian ini, namun seluruh alur dan plot dokumenter tersebut memberikan petunjuk filmis yang menghadirkan irisan antara fakta dan fiksi. Berangkat dari penyelidikan awal tersebut, maka penyelidikan lanjutan dilakukan melalui riset ini untuk mendapatkan hasil berupa operasional Faksi melalui metafora yang terdapat diseluruh teks.
} 
berkonflik, masyarakat vs pemerintah/pengelola taman nasional. ${ }^{4}$

"Para Harimau Yang Menolak Punah" sebagai film dokumenter produksi Eagle Institute meletakkan ciri khas penggunaan tuturan melalui pola wawancara terhadap aktor sosial yang digunakan, yang lebih dikenal sebagai gaya ekspositori. ${ }^{5}$ Sepanjang plot dalam dokumenter ini menceritakan upaya penyelamatan Taman Nasional Meru Betiri yang dilakukan oleh Wahyu Giri (seorang guru) dan Dainuri (lulusan pondok pesantren) untuk menciptakan kesadaran dalam mengantisipasi bencana pada alam. Pengamatan peneliti ditujukan pada unsur fakta dan fiksi yang dilihat melalui rangkaian gambar dan suara dalam film dokumenter ini. Unsur fakta dan fiksi yang terdapat dalam dokumenter merupakan pertimbangan bagi peneliti untuk membandingkan kesesuaian antara narasi tuturan dengan gambar.

Menurut peneliti, ada rangkaian narasi yang dimunculkan melalui judul dan adegan wawancara yang tidak menggambarkan situasi yang sama dengan kondisi sebenarnya. Peneliti menganggap bahwa narasi tersebut seolah mengungkapkan legitimasi atas peristiwa tertentu yang belum terbukti secara faktual antara judul dan gambar yang terekam di sepanjang film itu. Dalam wawancara kepada sutradara (Manda), peneliti menemukan bahwa makna Harimau yang dipilih sebagai judul adalah diksi yang tidak denotatif, namun bermakna konotatif. ${ }^{6}$ Dalam wawancara yang dilakukan peneliti, Manda menyiratkan bahwa yang dimaksud 'harimau' yang menolak punah" adalah Giri dan Dainuri sendiri. Bagi peneliti, tuturan yang muncul di sepanjang plot tersebut dapat dikatakan sebagai salah satu unsur fiktif yang terdapat dalam dokumenter. Tentu saja metafor semacam itu mengaburkan peristiwa yang sesungguhnya (Gambar 1). Hasil wawancara

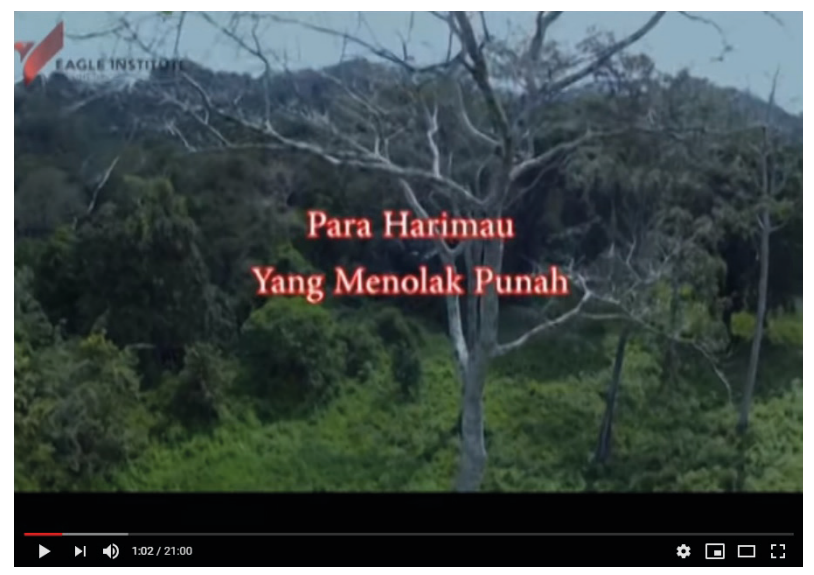

Gambar 1. Judul film. (Sumber: https://www.youtube. com/watch?v=rUUHg2Jb4zs)

4 Dalam penentuan narasumber yang ditampilkan dalam film, sutradara (Manda) memang lebih fokus pada Wahyu Giri dan Daynuri beserta Forkompac. Manda menyadari bahwa volume pihak Taman Nasional yang mewakili pemerintah, tidak begitu dimunculkan dalam film ini. Keberpihakan dan subyektifitas filmmaker pada gerakan penolakan tambang tidak dibantah oleh Manda. Wawancara dengan sutradara dilakukan dengan obrolan melalui aplikasi Whatsapp oleh Romdhi Fatkhur Rozi pada Agustus 2017.

5 Dokumenter ekspositori merupakan salah satu gaya dalam dokumenter yang menyertakan tuturan melalui penyatuannya dengan serangkaian gambar dengan tujuan agar lebih deksriptif dan informatif. Tuturan dalam hal ini berusaha menawarkan serangkaian fakta dan argumentasi melalui ilustrasi dalam shot-shot yang disisipkan dalam tuturan tersebut. Tuturan dapat berbentuk voice over maupun wawancara. Dokumenter ekspositori merupakan salah satu dari 6 gaya dokumenter yang dirumuskan oleh Bill Nichols (Nichols, 2001: 22).

6 Untuk pemilihan judul film, sutradara (Manda) menjelaskan sebagai berikut: "Harimau menjadi simbol mereka yang bergerak menyelamatkan Taman Nasional Meru Betiri dari ancaman tambang. Pemilihan simbol tersebut didasarkan kedekatan antara Harimau Jawa dan Taman Nasional Meru Betiri. Meru Betiri ditetapkan sebagai taman nasional, salah satunya, untuk melindungi Harimau Jawa agar tidak punah." Dalam wawancara ini, perspektif filmmaker tentang keyakinan bahwa harimau jawa belum punah, tidak dijelaskan. Manda lebih menekankan bahwa kapasitasnya sebagai filmmaker adalah untuk menangkap realitas bahwa menyelamatkan taman nasional dengan isu kearifan lokal merupakan salah satu solusi menghindari praktik penambangan. Hal ini termanifestasikan dalam wawancara dengan tokoh Wahyu Giri. Selain isu kearifan lokal, Manda juga menunjukkan usaha penyelamatan dari kegiatan penambangan melalui proses pendampingan masyarakat yang termanifestasikan dalam wawancara dengan tokoh Dainuri. Manda juga sepakat bahwa makna kata harimau dalam judul film merupakan makna konotatif, bukan denotatif. Harimau merupakan simbol mereka yang bergerak menyelamatkan taman nasional dari ancaman tambang. Wawancara dengan sutradara dilakukan dengan obrolan melalui aplikasi whatsapp oleh Romdhi Fatkhur Rozi pada Agustus 2017. 
peneliti kepada sutradara menemukan bahwa perspektif sineas tentang keyakinan harimau jawa belum punah, tidak dijelaskan. Manda lebih menekankan bahwa kapasitasnya sebagai filmmaker adalah untuk menangkap realitas bahwa menyelamatkan taman nasional dengan isu kearifan lokal merupakan salah satu solusi menghindari praktik penambangan. Terlepas dengan kekaburan yang terjadi, setidaknya melalui metafora yang disampaikan, sineas ingin menunjukkan adanya unsur estetis, sehingga dokumenter ini menarik karena kesan dramatisnya.

Selanjutnya pada potongan gambar berikut ini (Gambar 2 dan Gambar 3), seseorang bernama Dainuri dan Wahyu Giri yang disiratkan oleh sineas sebagai "harimau" (timeline 0.05-0.33 dan 0.51-0.59) menceritakan situasi dan kondisi pertambangan illegal di wilayah itu. Dalam cerita tersebut, Dainuri menyisipkan opini pribadi. Hal ini menjadi penanda bahwa telah muncul singgungan antara teks dan konteks saat aktor sosial mengemukakan fakta dan opini melalui tuturan.

Sementara pada potongan gambar di timeline 00.38, 02.31, 02.33, dan 12.39 ini peneliti menganggap bahwa situasi yang digambarkan dalam tuturan, merupakan upaya legitimasi tentang kebenaran cerita yang disampaikan pada timeline sebelumnya. Upaya tersebut peneliti anggap sebagai strategi yang dilakukan oleh sineas untuk menekankan kebenaran dalam film tersebut serta memperkuat fungsi estetis. Peneliti meyakini bahwa upaya legitimasi melalui pilihan-pilihan shot yang dilakukan oleh sineas menunjukkan bahwa

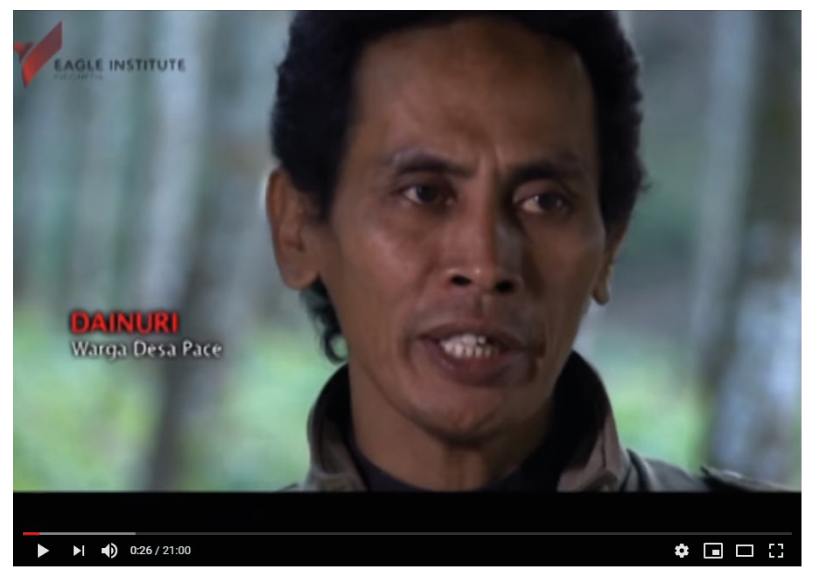

Gambar 2. Wawancara terhadap narasumber bernama

Dainuri. (Sumber: https://www.youtube.com/ watch?v=rUUHg2Jb4zs) suatu karya film dokumenter memiliki fungsi estetis secara sosial dan fisik (Feldman, 1967: 4-35). Secara sosial, film dokumenter mengandung pesan sosial yang dikemas secara sinematik untuk dapat dicerna dalam wilayah estetis penonton. Secara fisik, film dokumenter sebagai salah satu bentuk karya seni tidak akan meninggalkan unsur dan sifat estetis yang terdiri dari: bentuk (gaya) dan makna.

Selain wacana estetis yang melekat dalam film, dokumenter ini juga hadir di Indonesia dalam situasi politik pascareformasi. Era ini identik dengan kebebasan berpendapat dan berekspresi yang juga berpengaruh terhadap cara bertutur dan gaya ekspresi sutradara dalam menyampaikan pesan dan kritik sosialnya. Konteks politik yang dimaksud adalah era pasca reformasi, dan konteks bahwa film ini diproduseri oleh sebuah yayasan yang tujuannya melahirkan suatu gerakan publik yang konkrit berupa peran masyarakat sipil mengawal kehidupan berbangsa dan bernegara.

Film yang mengkritisi kehadiran penambang liar di Taman Nasional Meru Betiri ini merupakan perwujudan kontrol masyarakat dalam aktivitas kehidupan berbangsa dan bernegara. Dokumenter ini menggambarkan tentang perlawanan masyarakat atas ketidakhadiran pemerintah/negara dalam menangani penambang liar. Suatu kritik kepada negara yang pada era orde sebelum reformasi tidak begitu bebas dilakukan.

Dalam konteks ini, kritik melalui sajian dokumenter dilakukan oleh dua orang sutradara, yang pada saat film tersebut diproduksi masih

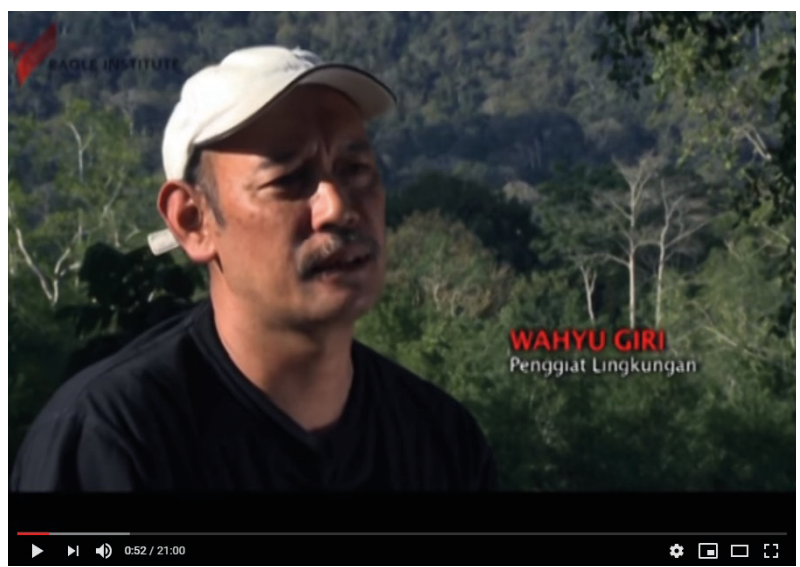

Gambar 3. Wawancara terhadap narasumber bernama Wahyu Giri. (Sumber: https://www.youtube.com/ watch? $=\mathrm{rUUHg} 2 \mathrm{Jb} 4 \mathrm{zs}$ ) 
berstatus sebagai mahasiswa di Fakultas Ekonomi Universitas Jember. Sineas mengembangkan naskah awal dengan menggunakan data awal yang didapat dari hasil liputan jurnalistik sebuah Unit Kegiatan Pers Mahasiswa Ecpose Fakultas Ekonomi Universitas Jember. "Para Harimau Yang Menolak Punah" juga merupakan produksi dokumenter pertama dari kedua orang sutradaranya. ${ }^{7}$

Selain itu, konteks politis pasca orba saat film dokumenter tersebut diproduksi dan dirilis juga berkelindan dengan ideologi krtisisme tertentu yang diusung yayasan yang memproduseri pembuatan film tersebut. Peneliti menemukan bahwa kedua sutradara yg melahirkan karya dalam kurun waktu pasca reformasi, tidak dapat mengetahui sejauh mana aspek politik pascareformasi mempengaruhi pembuatan karyanya. ${ }^{8} \mathrm{Hal}$ ini terjadi karena sineas belum pernah membuat karya dokumenter pada

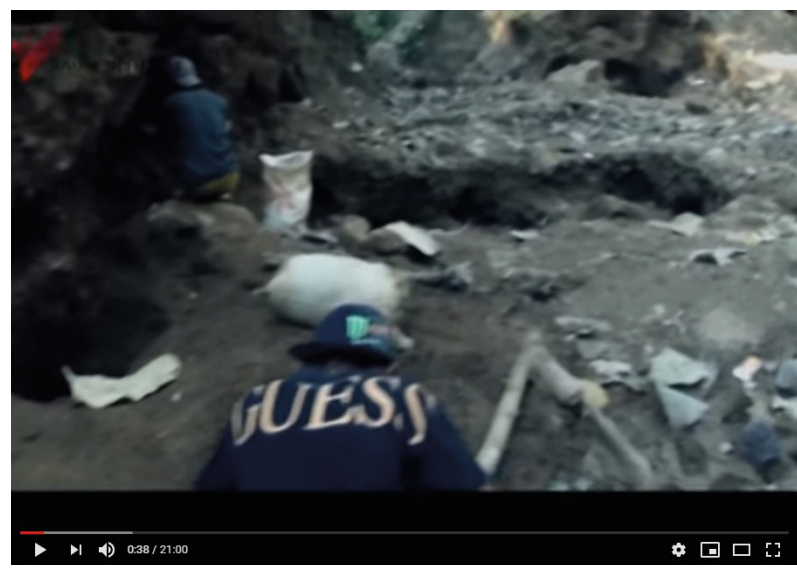

Gambar 4. Suasana penambangan liar di sekitar Meru Betiri. (Sumber: https://www.youtube.com/ watch?v=rUUHg2Jb4zs) situasi orde baru sehingga tidak dapat membedakan signifikansi pengaruh antara sebelum reformasi dan pascareformasi dalam tindakan kekaryaan.

Dari bentuk dokumenter yang ditawarkan, "Para Harimau Yang Menolak Punah" tetap menjadi seni estetis yang kritis, sekaligus propagandis (isu kearifan lokal via makna konotatif 'Harimau'), namun tidak dalam kepentingan penguasa, melainkan kepentingan masyarakat atas keasrian alam. Sehingga konteks politik yang dimaksud disini adalah bukan bagaimana era pasca reformasi mempengaruhi sineas. Kebebasan berekspresi di era pascareformasi menjadi iklim yang sesuai bagi institusi Eagle Award untuk membangun sinergi kritisisme dengan masyarakat (sineas muda) dalam memproduksi film dokumenter dengan ceritacerita inspiratif dari berbagai sudut pandang yang unik dan tegas.

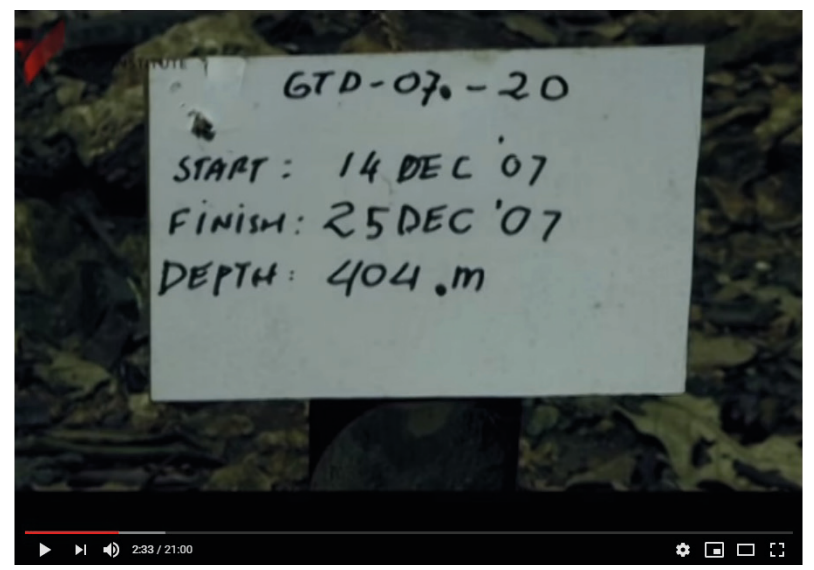

Gambar 5. Situasi Meru Betiri setelah tambang masuk di wilayah ini. (Sumber: https://www.youtube.com/ watch?v=rUUHg2Jb4zs)

\footnotetext{
Dalam wawancara oleh peneliti, Manda (sutradara) menjelaskan kronologis ide pembuatan film Produksi film dokumenter 'Para Harimau Yang Menolak Punah' diawali dari diskusi RTRW di Fakultas Sastra Universitas Jember (sekarang Fakultas Ilmu Budaya), bahwa ternyata kasus tambang yang diangkat dalam film, ternyata belum selesai. Kebetulan saat itu para filmmaker tergabung dalam Pers Mahasiswa Ecpose, dan Ecpose juga pernah mengangkat isu ini. Ecpose sendiri adalah UKM Pers Mahasiswa di Fakultas Ekonomi Universitas Jember tempat Manda menempuh studi S1-nya. Hasil liputan jurnalistik Ecpose, menjadi data pustaka awal untuk mengembangkan film dan penentuan narasumber. Dalam perumusan ide cerita hingga treatment dilakukan bersama-sama antara kedua Sutradara yaitu Imanda Dea Sabiella dan Edho Cahya.

8 Manda menambahkan, bahwa filmmaker memang menuangkan aspek estetis dan aktualitas di dalam treatment produksi. Manda memastikan bahwa kedua sutradara terlibat langsung dalam penentuan aspek estetis baik dalam produksi (pengambilan gambar) ataupun pasca produksi (editing). Namun aspek tersebut tetap bergantung pada realitas saat proses produksi dilakukan. Hal ini berkaitan dengan rentang waktu terbatas yang diberikan oleh pihak Eagle Award. Dalam film pertamanya ini, Manda tidak dapat memastikan apakah situasi pasca reformasi mempengaruhi pembuatan dan ekspresi yang akan disampaikan film dokumenter tersebut. Kritik yang disampaikan dalam film juga merupakan hasil diskusi dengan produser dan (dengan) pertimbangan dampak ke masyarakat. Dapat diasumsikan bahwa konteks politik pasca reformasi tidak begitu berpengaruh dalam penentuan keputusan dan ekspresi film.
} 


\section{Simpulan}

Ada persinggungan teks dan konteks dalam wilayah estetis dan politis. Aspek estetis termanifestasikan dalam (1) bentuk yang dihasilkan melalui teknik produksi, penyuntingan dan bagaimana hasil akhir disajikan. Dokumenter ini tetap memiliki subyektifitas dan keberpihakan sineas. Ia tidak seperti produk jurnalistik yang menganut cover both side, namun sengaja menonjolkan beberapa aspek dan menghilangkan yang lain. Sedangkan konteks politik yang menandai dokumenter era pascareformasi adalah adanya kecenderungan (2) toleransi terhadap keberadaan gagasan berdasarkan kepentingan yang selalu tertuang pada tema-tema EADC (Eagle Award Documentary Competition), sebagai gerakan publik yang konkrit untuk mengawal kehidupan berbangsa dan bernegara dengan ideologi kritisisme tertentu. Peneliti menemukan bahwa konteks politik pasca reformasi tidak mempengaruhi sineas dalam pengambilan keputusan ide, tema, dan ekspresi sinemanya karena karya ini sebagai karya pertama yang baru dibuat dalam kurun pacsa reformasi. Namun konteks politik dokumenter era pascareformasi menciptakan (3) negosiasi pada penciptaan iklim yang sesuai bagi institusi Eagle Award untuk membangun sinergi kritisisme dengan masyarakat (sineas muda) dalam memproduksi film dokumenter dengan cerita-cerita inspiratif dari berbagai sudut pandang yang unik dan tegas.

\section{Ucapan Terima Kasih}

Kami menyampaikan terima kasih kepada: (1) Universitas Jember atas fasilitas dana penelitian; (2); Asosiasi Pengkaji Film Indonesia (Kafein) yang telah memberikan saran dan masukan bagi penulisan artikel ini; (3) Tito Imanda, M.A., PhD. selaku konsultan bagi penulisan artikel ini; dan (3) Imanda Dea (Sineas), selaku narasumber.

\section{Kepustakaan}

Abdenour, J. (2014). Documenting Fair Use: Has the Statement of Best Practices Loosened the Fair Use Reins for Documentary Filmmakers? Communication. Law and Policy, 19:3, $367-$
398. Doi: http://dx.doi.org/10.1080/10811 680.2014 .919813

Barone, T. (2003). Challenging the Educational Imaginary: Issues of Form, Substance, and Quality in Film-Based Resea. Qualitative Inquiry, Volume 9 Number 2, 2003 202-217. Doi: http://dx.doi.org/10.1177/1077800402 250931

Beattie, K. 2004. Documentary Series: Non-fiction Film and Television. New York: Palgrave Mac Millan.

Blumenberg, R. M. (1977). Documentary Films and the Problem of "Truth". Journal of the University Film Association, Vol. 29, No. 4. Stable URL: http://www.jstor.org/ stable/20687386

De Caro, M. dan Enrico Terrone. (2016). The View From Outside: On a Distinctively Cinematic Achievement. Philosophy and Social Criticism 2016, Vol. 42(2) 154-170. Doi: http://dx.doi. org/10.1177/0191453715588993

Deogracias, J.C.S. dan Javier Mateos-Pérez. 2013. Thinking About Television Audiences: Entertainment and Reconstruction In Nature Documentaries. European Journal of Communication 28(5) 570-583. Doi: http:// dx.doi.org/10.1177/0267323113494075

Fredriksson, A. (2010). Documentary Film Beyond Intention and Re-Presentation: Trinh T. Minhha and the Aesthetics of Materiality. Journal of Information Ethics / Volume 19, Number 2 / Fall 2010 / pp. 67-81 / ISSN 1061-9321 (Print) / ISSN 1941-2894 (Online) / C 2010 McFarland \& Company, Inc. doi: http:// dx.doi.org/10.3172/JIE.19.2.67

Michelle, C. 2007. Modes of Reception: A Consolidated Analytical Framework, The Communication Review, 10:3, 181-222, Doi: http://dx.doi.org/10.1080/107144207015 28057

Irawanto, B. 2012. Beyond Big Dramatic Moments: Indonesian Documentary Films in the $21^{\text {st }}$ Century. Busan: Busan International Film Festival.

Kartika, B. (2015). Mengapa Selalu Harus Perempuan: Suatu Konstruksi Urban Pemenjaraan Seksual Hingga Hegemoni 
Maskulinitas dalam Film Soekarno. Journal of Urban Society's Arts, 2(1), 35-54. doi:http:// dx.doi.org/10.24821/jousa.v2i1.1268

Kuehl, J. dan Alan Rosenthal (ed). 1988. Truth Claims-New Challenge for Documentary: The Voice of Documentary. Berkeley: University of California.

Lehar, S. 2003. The World in Your Head: A Gestalt View of the Mechanism of Conscious Experience. London: Lawrence Elbaum Associates Publisher.

Lerner, J. dan Juhasz, Alexandra (eds). 2006. F is for phony: fake documentary and truth's undoing. Minneapolis: University of Minnesota Press

Nichols, B. 2001. Introduction to Documentary. Bloomington: Indiana University Press.

O'Flynn, S. (2012). Documentary's metamorphic form: Webdoc, interactive, transmedia, participatory and beyond. Studies in Documentary Film. 6:2, 141-157. http:// dx.doi.org/10.1386/sdf.6.2.141_1

Persson, P. 2003. Understanding Cinema: A Psychological Theory of Moving Imagery. Cambridge: Cambridge University Press.

Plantinga, C. (2002). Cognitive Film Theory: An Insider's Appraisal. Cinémas, 12(2), 15-37. Doi: http://dx.doi.org/10.7202/024878ar

Pramaggiore, M. (2011). A Review of "Documentary Display: Reviewing Nonfiction Film and Video". Quarterly Review of Film and Video, 28:5, 433-438. Doi: http://dx.doi. org/10.1080/10509200902820597

Renov, M. 1993. Theorizing Documentary. London\&New York: Routledge.

Richards, M. (2014). The Wildlife Docusoap: A New Ethical Practice for Wildlife Documentary? Television \& New Media 2014, Vol. 15(4) 321-335. Doi: http://dx.doi. org/10.1177/1527476412465656

Rosenthal, A. 1988. New Challenge For Documentary.
Berkeley: University of California Press. Schoen, S. W. dan David S. Spangler. (2011). Making Sense Under a Midnight Sun: Transdisciplinary Art, Documentary Film, and Cultural Exchange. CulturalStudies $<->$ Critical Methodologies 11(5) 423-433. Doi: http:// dx.doi.org/10.1177/1532708611423206

Setyowati, L. (2017). Bahasa Visual dalam Sinetron Indonesia. Journal of Urban Society's Arts, 4(1), 19-28. doi:http://dx.doi.org/10.24821/jousa. v4i1.1491

Silbey, J.. (2014). Persuasive Visions: Film and Memory. Law, Culture and the Humanities 2014, Vol 10(1) 24-4. Doi: http://dx.doi. org/10.1177/1743872111423175

Vulkanita Hasan, R., \& Raharsono, A. (2016). "Joki Kecil": Fakta dan Fiksi Dalam Sudut Pandang Kognitif. Imaji, 14(2), 164 - 171. doi: $\quad$ http://dx.doi.org/10.21831/imaji. v14i2.12180

Williams, L.. (1993). Mirrors without Memories: Truth, History, and the New Documentary. Film Quarterly, Vol. 46, No. 3 (Spring, 1993). Stable URL: http://www.jstor.org/ stable/1212899

\section{Filmografi}

Para Harimau Yang Menolak Punah, 2013, Sutradara: Imanda Dea Sabiella dan Edho Cahya Kusuma (Durasi: 21 menit, Sumber: Eagle Institute via https://www.youtube. com/watch?v=rUUHg2Jb4zs, Diakses: 11 September 2016).

\section{Informan}

Imanda Dea Sabiella. Sutradara film "Para Harimau Yang Menolak Punah”, dilakukan oleh Romdhi Fatkhur Rozi pada Agustus 2017. 